\section{La migración como temática en el cine actual}

SHANNON ESTEFANNIA

Casallas Duque

paris_606@hotmail.com

Universidad Distrital

Francisco José de Caldas, Colombia

FECHA DE RECEPCIÓN febrero 12,2019

FECHA DE APROBACIÓN junio 10, 2019

https://doi.org/10.32870/ elojoquepiensa.v0i19.304
Resumen / Durante la última década y debido al fenómeno migratorio masivo que ha ocurrido a nivel global, las producciones cinematográficas han adoptado diversos enfoques para traer las historias de este nuevo grupo demográfico a la pantalla grande. Sin embargo, la perspectiva desde la cual se presenta la información tiene el poder de cambiar la percepción de los espectadores respecto a la situación y a los involucrados. Es por esta razón que este estudio propone analizar cuatro formas en las cuales se están representando a los inmigrantes y refugiados en el cine actual además de reflexionar sobre el nuevo rol del séptimo arte como herramienta de denuncia social, y abrir a la vez la discusión sobre la ética y el compromiso social de los cineastas al momento de abordar temas relacionados con el actual estado sociopolítico nacional e internacional.

PalabRas Glave / refugiados, inmigrantes, representación.
Abstract / During the last decade and due to the massive migration phenomenon that has occurred globally, film productions have adopted various approaches to bring the stories of this new demographic group to the big screen. However, the perspective from which the information is presented has the power to change the perception of the viewers regarding the situation and those involved. It is for this reason that this study proposes to analyze four ways in which immigrants and refugees are being represented in today's cinema as well as reflecting on the new role of the seventh art as a tool for social denunciation, and at the same time opening the discussion on ethics and social commitment of the filmmakers when addressing issues related to the current national and international socio-political state.

KEYWORDS / refugees, immigrants, representation. 
posibles comparaciones y contrastes entre estos. Finalmente, se presentará una reflexión en torno al papel del cine como testigo de las realidades a lo largo del globo y su función como herramienta para la protesta social [FIGURA 1].

En la primera parte de este plano cartesiano tenemos en la izquierda y como no, al cine independiente. Este tipo de cine se puede considerar un rebelde en la industria ya que busca nuevos desafíos, ofrece una mirada de los conflictos alrededor del mundo y está dispuesto a salirse de la tradición cinematográfica idealista para explorar otros horizontes con historias impopulares. Su financiación se encuentra principalmente en los bolsillos de emprendedores que se arriesgan con cintas de bajo presupuesto y cuya labor es contar historias incómodas que generen preguntas y cuestionamientos sobre las maquinarias políticas, económicas, educativas, culturales e históricas que gobiernan el mundo. $\mathrm{El}$ cine independiente es un contendiente fuerte no en recursos pero en estructura porque da cabida y ofrece exposición a las poblaciones vulnerables, a las narrativas parias, a los enajenados sociales.

Por lo general, las cintas independientes cuentan historias de los conflictos del ser humano en el día a día como la sexualidad en Luz de luna (Moonlight, Barry Jenkins, 2016), la guerra en Silenciado (Silenced, James Spione, 2014), el desamor en Krisha (Trey E. Shults, 2016), la crisis de valores en El proyecto Florida (The Florida Project, Sean Baker, 2017), el miedo en ¿Las calles de quién? (Whose Streets?, Sabaah Folayan, 2017) o la religión en Mustang: Belleza Salvaje (Mustang, Deniz Gamze Ergüven, 2015). Todas estas películas inician su reflexión en torno a temas particulares desde la disección de los personajes y continúan con un estudio de lo que significa ser un ser humano en tejidos sociales interconectados, donde la mayoría se lleva por delante a las minorías y las obliga a hacer parte de la heterogeneidad que amenaza con extinguir las virtudes individuales, eliminando el derecho a la protesta y el levantamiento de la oposición de forma simultánea.

Sin embargo y aunque el cine independiente se encuentra en un terreno fértil en lo que respecta a temas y perspectivas,

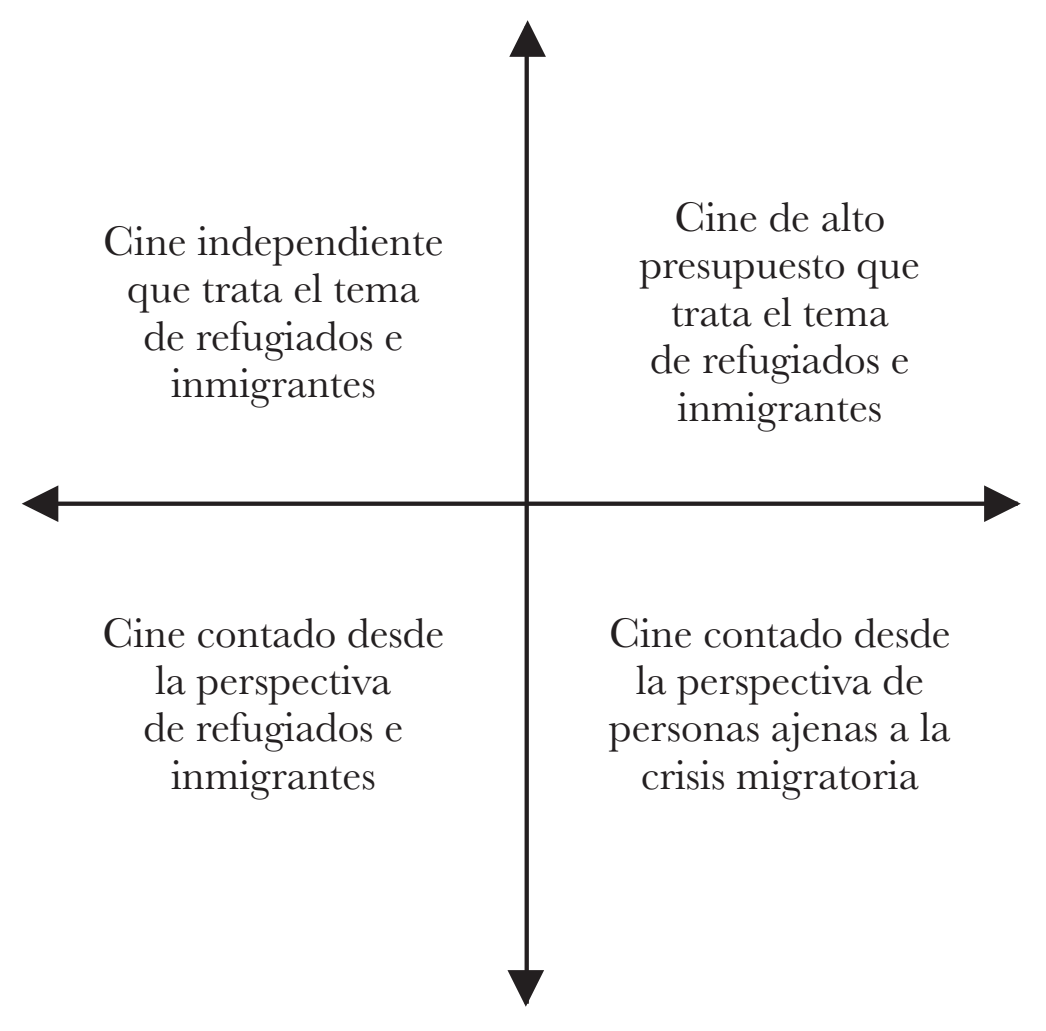

FIGURA 1. Plano cartesiano de los puntos de vista desde los que se han representado en el cine a los migrantes y refugiados.

no es un tipo de cine popular en occidente, donde Hollywood controla una gran parte del mercado. Es por esta situación particular que varios países en Europa, América Latina y otras latitudes, se han convertido en generadores constantes de cine de bajo presupuesto y además, trabajan en fomentar desde hace varios años atrás espacios para la visualización y reconocimiento del mismo. Un ejemplo de este esfuerzo son los diferentes festivales como Cannes, Berlín, Venecia, San Sebastián, Zúrich, Immigration Film Festival, London Migration Film Festival, Festival of Migrant Film, Films Across Borders, San Francisco Immigrant Films Festival, entre otros, que sirven como plataformas para publicitar a nivel local, nacional e internacional, las cintas de temáticas políticas y humanitarias que se han popularizado en las últimas dos décadas.

En estos escenarios, el cine se utiliza como herramienta de revolución social para exponer las razones por las que estas grandes migraciones están ocurriendo, la precariedad de la situación de los inmigrantes y refugiados en las travesías de escape, además de los abusos a los que son sometidos por su 
situación de ilegalidad y las posibles soluciones a mediano y largo plazo para aliviar esta situación.

Es debido a la multiculturalidad global y a las iniciativas que incentivan a los nuevos directores a dar una mirada a los problemas sociales que acogen a la población, que las películas relacionadas a temas de inmigración, refugiados, cambios sociales, malestar político, inestabilidad económica, prácticas culturales y religiosas que van en contra de los derechos humanos y los derechos del niño, han tenido una plataforma para dar luz sobre problemáticas que tienen lugar en los cuatro puntos cardinales.

El cine independiente está dando voz a las víctimas de la crisis migratoria, quienes son resultado de la corrupción y manipulación internacional mientras el mundo observa silente y aprende sobre el odio al otro, ya que las formas en las que los inmigrantes y refugiados son representados en la cotidianidad por medio de informes periodísticos y noticias están llenos de violencia y terror, generando así estigmas y xenofobia en la población civil que se encuentra en la dicotomía del bombardeo periodístico y la falta de información objetiva de primera mano. Enrique Martínez-Salanova, pedagogo y miembro de Amnistía Internacional, hace énfasis en que la información ofrecida al público, origina opiniones perjudiciales y desinformación:

En nuestra sociedad hemos internalizado profundamente la opinión de que los fenómenos migratorios están asociados al incremento del índice de inseguridad social y de delincuencia. Y de ello tienen mucha culpa los medios de comunicación, a veces recogiendo informaciones de la boca de algunos políticos de la derecha, que constantemente - al hilo de la noticia- van sembrando la especie de que en donde hay un delito hay emigrantes, sin pararse a reflexionar que también donde hay un accidente laboral siempre hay -desgraciadamente- emigrantes (2008, p. 3).

Por otro lado, son bastantes los documentales de mediana y corta duración y pocos los largometrajes que logran contar estas historias porque se encuentran principalmente con dos obstáculos: el primero, la financiación y el segundo, la distribución. Los lazos económicos, el señalamiento público y el cuestionamiento de las políticas nacionales e internacionales hacen que los inversionistas den un paso hacia atrás y prefieran cuidarse y cuidarle la espalda a los líderes políticos cuya corrupción ha transgredido la industria cinematográfica para incluirla en el negocio de la propaganda mediática. Adicionalmente, al buscar material cinematográfico sobre refugiados e inmigrantes en la web o en las calles, la mayoría de los títulos son difíciles o casi imposibles de conseguir porque son poco conocidos o de origen independiente por lo que su distribución ha sido casi nula. El material producido a lo largo del globo que expone las condiciones inhumanas en las que viven millones de personas, resultado de la guerra entre poderosos, no encuentra salida al mercado transcultural global porque no es considerado importante o un contendor fuerte para competir contra el monopolio hollywoodense en la taquilla mundial.

Un ejemplo de esta situación se encuentra en la página web de Amnistía Internacional, en la cual se encuentra el artículo: "7 cortometrajes gratuitos sobre refugiados, recomendados por educadores de derechos humanos", escrito por Camille Roch en marzo de 2016, donde se enlistan siete cortometrajes y sus enlaces para ocuparse del tema de los derechos humanos desde la perspectiva del refugiado: People of Nowhere (Lior Sperandeo, 2015), Seeking Refugee: Ali's Journey From Afghanistan (Andy Glynne, 2012), Then I Came by Boat (Marleena Forward, 2014), Malak and the Boat (André Holzmeister, 2016), A Life on Hold (Nick Francis y Marc Silver, 2012) y When You Don't Exist (John Denver, 2013), son cortos que muestran el conflicto en tierras extranjeras desde voces individuales que reconstruyen su pasado y el momento en el que tuvieron que huir para no perecer. Un solo personaje que con su voz, fotografías viejas y momentos de animación y caricaturas, logra conectar con el observador y dejar un mensaje claro y simple: un refugiado es un ser humano con un pasado que busca un futuro. Empero, esta 
información se pierde por falta de exposición y un público al cual entregar el mensaje.

Ahora bien, se debe reconocer que el cine independiente con temáticas de inmigración y refugiados, se han abierto paso en las grandes ligas por medio de una brecha en las categorías de Mejor Película Animada y Mejor Película de Habla no Inglesa en los Premios de la Academia en Estados Unidos. En los últimos 13 años, películas como El castillo ambulante (Howl no Ugoku Shiro, Hayao Miyazaki, 2005), Persépolis (Persepolis, Marjane Satrapi y Vincent Paronnaud, 2007), El secreto del libro de Kells (Book of Kells, Tomm Moore y Nora Twomey, 2010), Chico y Rita (Fernando Trueba, Javier Mariscal y Tono Errando, 2011), Se levanta el viento (Kaze Tachinu, Hayao Miyazaki, 2013) y The Breadwinner (Nora Twomey, 2017), han sido nominadas en la categoría de Mejor Película Animada. Estas cintas recurren al artefacto infantil de la ilustración para mostrar la deshumanización de la guerra y los abusos a los que se ven expuestas las víctimas de conflictos internacionales. Este hecho ha permitido popularizar estas historias y ganar un espacio en el mercado global ya que al estar nominadas, la cultura pop las acepta y las vuelve populares, contribuyendo a su distribución masiva y el subsecuente conocimiento del horror de la guerra por parte de la población mundial.

En estas películas se muestra a los refugiados e inmigrantes como sobrevivientes y luchadores que no buscan aprovecharse de los recursos ajenos sino una oportunidad para ganarse un lugar en el nuevo mundo. Desafortunadamente, esta oportunidad se ve restringida por factores de nacionalidad, raza, creencias y género.

En lo que respecta a la categoría de Mejor Película de Habla no Inglesa, películas nominadas y ganadoras como En un lugar de África (Nirgendwo in Afrika, Caroline Link 2001), Tsotsi (Gavin Hood, 2005), La clase (The Class, Laurent Cantet, 2008), Vals con Bashir (Vals Im Bashir, Ari Folman, 2008), La cinta blanca (Dasweisse Band, Michael Haneke, 2009), En un mundo mejor (Hevnen, Susanne Bier, 2010), Biutiful (Alejandro
González Iñárritu, 2010), Una separación (Yodaí-e Nader az Simin, Asghar Farhadi, 2011), Profesor Lazhar (Monsieur Lazhar, Philippe Falardeau, 2011), La imagen ausente (Limage manquante, Rithy Panh, 2013), Omar (Hany Abu-Assad, 2013), Timbuktú (Timbuktu, Abderrahmane Sissako, 2014) y El hijo de Saúl (Saul fia, László Nemes, 2015) entre otras, son narrativas que muestran la complejidad de este fenómeno social desde las perspectivas de los inmigrantes y refugiados, evitando catalogarlos como víctimas y exponiendo las consecuencias de la guerra sobre la población civil.

Galiano León (2008) se refiere al cine de migración como "Un medio que representa de forma crítica, las dificultades de adaptación a esa otra nueva forma de vida ya que esto conlleva siempre una serie de problemas sociales y humanos de profundo calado" (p. 177). De este modo, estas formas de representación son accesibles al público internacional por medio de una acción tan simple como comprar un boleto y ver una película.

Si bien en décadas anteriores la mayoría de cintas habían mostrado casi exclusivamente la devastación que han causado la guerra y el genocidio en África a manos de pandillas populares, grupos armados, gobiernos ilegales, cascos azules corruptos, etcétera, por medio de imágenes que causaron escozor y mutaron en rechazo por parte del observador, estos horrores se están moviendo hacia occidente y el cine es ahora una herramienta para la denuncia de los flagelos que se cometen en contra de los que huyen, mostrándolos como seres humanos en busca de igualdad y justicia, y exponiendo también a los culpables, mientras hace frente a la venta mediática del falso terrorismo de Oriente.

Se podría afirmar entonces y a partir del análisis anterior, que el cine independiente a pequeña y gran escala continúa con su labor social al darle un espacio a estas temáticas e impulsándolas por medio de festivales y el voz a voz entre los fieles del cine de contenido social y político. Igualmente, este tipo de cine trae a la mesa discusiones que en algunos casos logran generar iniciativas de apoyo que se materializan 
FIGURA 2. Dheepan (Jaques Audiard, 2015). La película cuenta la historia de un exguerrillero de Sri Lanka que llega a Francia y se enfrenta a los problemas sociales al interior del país. La película fue ganadora de la Palma de Oro en el Festival de Cine de Cannes en 2015.

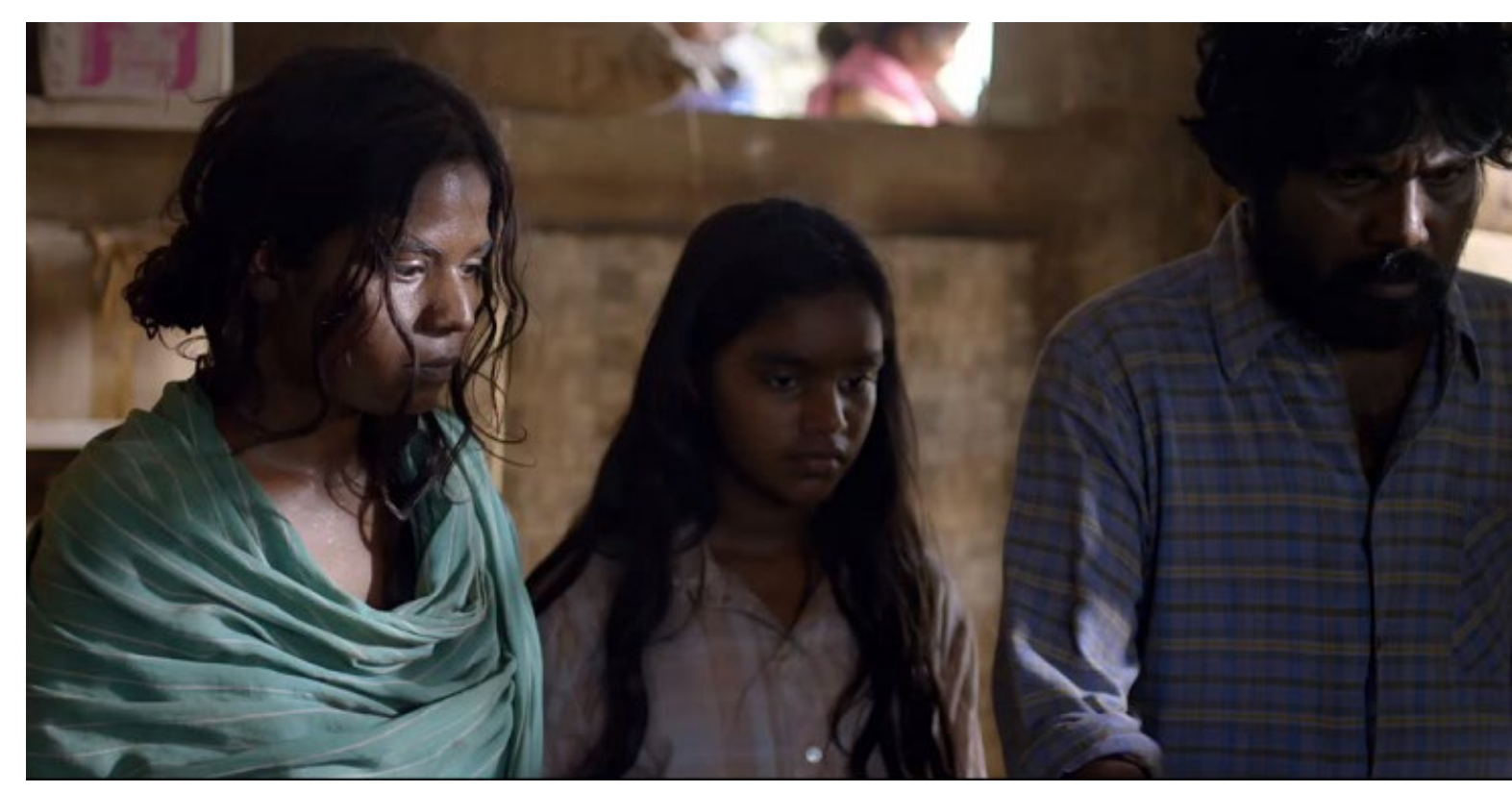

en Organizaciones No Gubernamentales. Estas entidades buscan brindar asistencia a personas en condición de vulnerabilidad y necesidad, además de fomentar la creación de empleos, donaciones y colectas de menesteres. Empero, la labor más importante del cine independiente que aborda la temática de los inmigrantes y los refugiados es promover el establecimiento de relaciones de empatía hacia otros en la cotidianidad [FIGURA 2].

Para continuar con el estudio de los ítems en el plano cartesiano, se analizará ahora y en contraste al ítem anterior, cómo es abordado el tema de inmigrantes y refugiados en el cine de alto presupuesto. Este tipo de cine por lo general proviene de Hollywood, ya que ahí se encuentran las mayores productoras de cine en el mundo, como por ejemplo: Warner Bros, Walt Disney Pictures, Universal Studios, 20th Century Fox, solo por nombrar algunas, y su contenido es consumido a nivel global.

En los últimos años, la industria Americana ha iniciado un frenesí para revivir superhéroes y villanos de comics, realizando películas biográficas y produciendo secuelas y spin off de clásicos. Sin embargo, esta corriente deja ver que el gigante de contenido audiovisual ha decidido dar la espalda a lo que ocurre en la actualidad, negando la producción y distribución masiva de películas con contenido social y de denuncia directa hacia el nuevo panorama internacional. Tal vez esta corriente es una respuesta a la sobre explotación de los medios de comunicación en lo que respecta a los conflictos internacionales y las crisis internas que inundan la televisión, los medios impresos y las redes sociales -tal vez-. No obstante, la negativa de Hollywood de asomarse a la ventana internacional ha dejado un vacío en la representación del nuevo grupo demográfico mundial: los inmigrantes y refugiados provenientes de los cuatro puntos cardinales.

Monica Castillo publicó en octubre de 2017 en el diario The New York Times el artículo "Hollywood's Diversity Problem and Undocumented Immigrants" (El problema de la diversidad de Hollywood y los inmigrantes indocumentados) en donde señala que si bien la migración es parte de la historia de la fundación de Hollywood y es un tema sobre el cual se realizaron varias películas durante las primeras décadas, este tipo de contenido parece haber sido censurado por la industria que además, se ha mantenido al margen de contar historias cuya temática es objeto de controversia actual y que necesita de perspectivas. 
Y no es que Hollywood no haya tenido su buena dosis en las últimas décadas con películas que presentan el tan anhelado sueño americano, ejemplos de esto son El Padrino II (The Godfather: Part II, Francis Ford Coppola, 1974), Moscú en Nueva York (Moscow on the Hudson, Paul Makurzy, 1984), Un cuento americano (An American Tail, Don Bluth, 1986), Un príncipe en Nueva York (Coming to America, John Landis, 1988), Titanic (James Cameron, 1997), Bailando en la oscuridad (Dancer in the Dark, Lars von Trier, 2000), Pandillas de Nueva York (Gangs of New York, Martin Scorsese, 2002), Tierra de sueños (In America, Jim Sheridan, 2003), La terminal (The Terminal, Steven Spielberg, 2004), Babel (Alejandro González Iñárritu, 2006), Sueños de libertad (The Immigrant, James Grey, 2013), Brooklyn: un nuevo hogar (Brooklyn, John Crowley, 2015) solo por mencionar algunas de las más importantes películas en la taquilla referentes al tema de inmigración y refugiados antes del nuevo milenio.

Estas fueron cintas que consiguieron encantar al espectador con la promesa de un mejor mañana en la tierra de las oportunidades pero es precisamente este aspecto el que hace de todo el tema una paradoja, ya que si bien estas películas abordan la inmigración y la búsqueda de refugio en tierras extranjeras, no terminan de presentar de forma realista lo que vive un inmigrante en su peregrinación y búsqueda de asilo. Hay demasiada estilización, una ensoñación idealista que promete el final feliz con una lucha meramente superficial donde el amor, el perdón y la esperanza lo pueden todo pero la realidad no es así, las oportunidades para que los inmigrantes y refugiados tengan una nueva vida no se encuentran en calles o favores, son pocas y hay que pelear por ellas contra los gigantes burocráticos, la corrupción y la xenofobia.

Diamante de sangre (Blood Diamond, Edward Zwick, 2006), El último rey de Escocia (The Last King of Scotland, Kevin Macdonald, 2006), Beasts of No Nation (Cary Fukunaga, 2015) o Él me nombró Malala (He named me Malala, Davis Guggenheim, 2015) son producciones reconocidas a nivel mundial por los realizadores y actores que aparecen en ellas. Aclamadas por la crítica y nominadas a premios internacionales, estas cintas presentan el conflicto interno de países cuyos gobiernos son corruptos y están asociados con genocidas nacionales e internacionales. Así mismo, muestran el papel de los organismos internacionales y las fallas en los sistemas legislativos que promueven a través de tratados de comercio y compras ilegales de materia prima, la explotación de tierras extranjeras, el uso de niños y niñas para trabajos forzados y el desplazamiento interno forzado de miles de familias que terminan en campos de refugiados, sumándose así a las generaciones huérfanas criadas en el conflicto y la violación de derechos humanos, esperando ayuda que es robada o negada mientras sufren las constantes amenazas de las guerrillas de izquierda y de derecha.

No obstante, lo que diezma el posible impacto de estas películas como forma de denuncia y evita el debate para generar presión sobre entidades internacionales que entren a ayudar a la población civil, es que la guerra y sus víctimas quedan aisladas y son opacadas por la figura del hombre blanco que se ve inmerso en una tragedia de la que busca ser héroe o por la que se sacrifica o es sacrificado. Entonces, las víctimas ya no son los personajes que padecen la guerra y deben huir para sobrevivir sino que se les convierte en el monstruo salvaje que viene a consumir a occidente con sus formas barbáricas [FIGURA 3].

Si bien hay un enemigo señalado abiertamente, no ocurre nada porque la ficción de la historia supera la denuncia de las situaciones de vulnerabilidad en las que se encuentra una parte de la población mundial. Adicionalmente, los espectadores ya han naturalizado dichas realidades debido a la sobreexposición de violencia y guerra en los medios de comunicación por lo que las historias no tienen el impacto deseado. Se debe entender que las potencias que sufragan el conflicto armado no se derrocan con discursos en premiaciones, hace falta movimiento en masa, hace falta pasar de la denuncia a la acción, pero ¿cómo? 

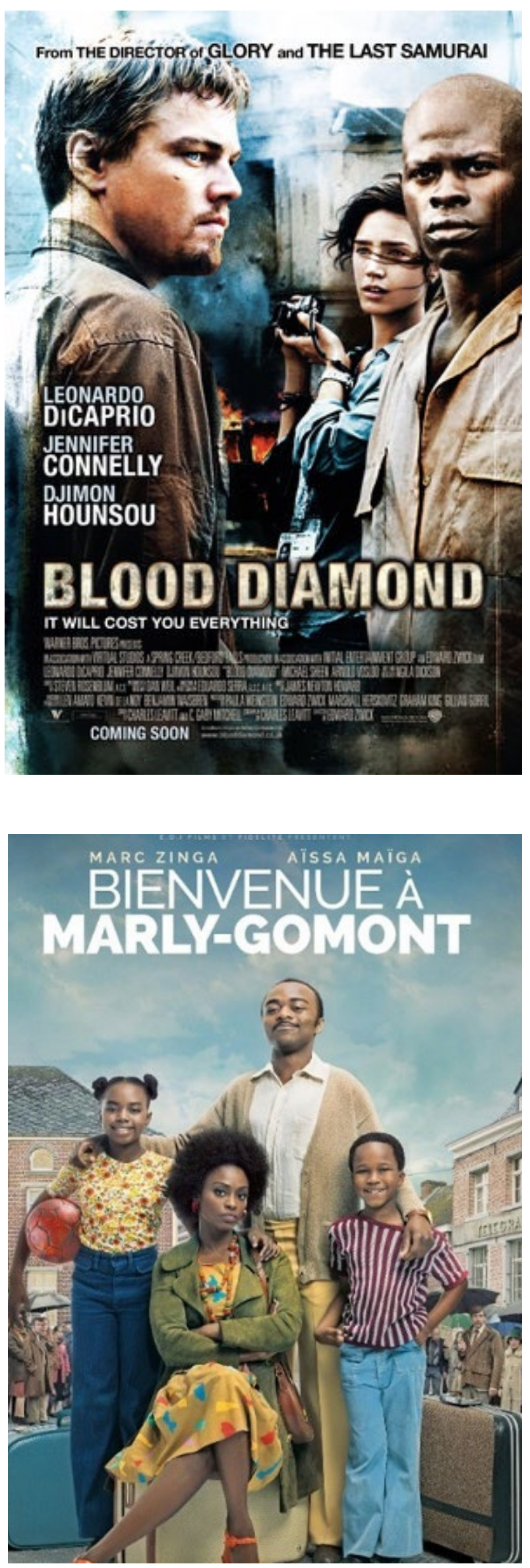

FIGURA 3. Diamante de sangre (Blood Diamond, Edward Zwick, 2006). El poster de la película está dividido en dos: a la izquierda se muestra al héroe blanco, y a la derecha se ve a los otros dos protagonistas. No hay énfasis en el conflicto de los diamantes de sangre o sus víctimas.
FIGURA 4. El médico africano (Bienvenue à Marly-

Goumont, Julien Rambaldi, 2016). En el poster se ve a la familia de origen congolés rodeada de franceses que los miran con extrañeza desde la distancia. 
Un ejemplo del movimiento masivo ${ }^{1}$ para la denuncia en contra de políticas que traen injusticia a la población migrante y de refugiados, es el de los latinos en Hollywood. Actores reconocidos en Latinoamérica e Iberoamérica como Gael García Bernal, Salma Hayek, Diego Luna, Javier Bardem, Penélope Cruz, y directores galardonados con el Óscar como Alfonso Guarón, Alejandro González Iñárritu y Guillermo del Toro, han abogado por protestar y buscar la erradicación de las nuevas políticas xenófobas por parte del presidente Donald Trump, quien en su discurso ha dejado ver una tendencia a la idea de la supremacía blanca y el nacionalismo exacerbado cuyos objetivos inmediatos son los extranjeros, inmigrantes y refugiados políticos.

Este grupo de personalidades, usando su reconocimiento a nivel internacional como plataforma para realizar intervenciones, trabajos de creación cinematográfica, denuncias, entre otros, le han recordado a la población norteamericana y al mundo que Estados Unidos es una tierra fundada en la multiculturalidad y la posibilidad de trabajar para conseguir un sueño.

La migración es un fenómeno social natural que ha permitido tejer lazos entre diferentes naciones a lo largo de la historia y el cierre de fronteras crea situaciones que van en contra de la dignidad humana, generando crisis innecesarias y segregaciones que recuerdan situaciones como la legalidad de la esclavitud hasta 1948, cuando la ONU la abolió por medio de la Declaración de los Derechos Humanos; el movimiento de las sufragistas para hacer que el gobierno reconociera los derechos de las mujeres legalmente (derechos que todavía son negados en Brunei, Emiratos Árabes Unidos y Ciudad del Vaticano); el matrimonio infantil en Asia Meridional, zonas

\footnotetext{
${ }^{1}$ Hollywood ya dio un ejemplo de cambio de paradigmas con los movimientos Me Too y Time's Up, ambos en respuesta a denuncias de acoso sexual y desigualdad en la industria del cine, la música, la política, las ciencias y la academia. Varias actrices, productoras, directoras, deportistas y mujeres en posiciones importantes en el gobierno dieron voz a esta denuncia social que ejerció presión sobre las ramas legislativa y ejecutiva para cambiar el castigo a los agresores además de hacer caer a uno de los más importantes productores de la industria, Harvey Weinstein.
}

de África oriental y occidental, Estados Unidos, entre otros países; y la consideración de la homosexualidad como enfermedad mental por parte de la Organización Mundial de la Salud hasta 1990 y su posterior despenalización en 2003.

Con esto se demuestra que la industria cinematográfica de alto presupuesto puede dar más de lo que ha dado hasta ahora y que su compromiso con el nuevo escenario internacional va desde el cambio de paradigmas en la producción y distribución, pasando por el refinanciamiento de proyectos de oriente y occidente, sur y norte hasta el activismo político. No se puede seguir dando placebos a la población con películas de animación que muestran otros mundos ideales cuando el nuestro está siendo desangrado por el capitalismo y el genocidio; la audiencia debe despertar con historias e imágenes que lleven un mensaje de urgencia que incite la acción común.

En el artículo "Hollywood ya no vende: El cine se enfrenta a su peor año en un siglo", publicado en la revista Vanity Fair en junio de 2016, que habla sobre el bajo registro en taquilla y la caída de Hollywood por el reciclaje de las historias, se menciona también que los espectadores van a cine para tener una experiencia y reclaman el despertar de los sentidos, ya que quieren ser sorprendidos por los personajes y la ficción. Esta es una oportunidad para que los cineastas, sin necesidad de recurrir al morbo y la sangre -al estilo Tarantino-, presenten largometrajes con los que el cinéfilo tropiece y dejen un sin sabor para de esta forma, fomentar acciones ofreciendo posibilidades reales de apoyo: páginas para donaciones de dinero y recursos, nombres de ONGs para el recibimiento de inmigrantes, programas de apoyo y relocalización de la población en estado de vulnerabilidad y cualquier otro tipo de movimiento masivo que se considere útil para aliviar la crisis y ayudar a los damnificados.

El cine de alto presupuesto proveniente de Hollywood ha logrado hasta ahora eludir su participación de forma directa para abogar a favor de las víctimas en el conflicto mundial, escondiéndose tras ensoñaciones de mundos utópicos, evitando tomar una posición definitiva y trabajar en pro del 
mejoramiento de la situación de los inmigrantes y refugiados que se ha catalizado en las últimas dos décadas por la falta de compromisos y soluciones tangibles por parte de las potencias mundiales en lo que respecta a la migración y los conflictos internacionales. Es tiempo para que los realizadores de renombre al igual que los actores y todo aquel que tenga tanto el presupuesto como el reconocimiento, se unan al unísono y reconozcan la crisis migratoria que ha tomado lugar en esta última década, dando voz a aquellos que son censurados por los medios, atrayendo la atención necesaria para aliviar el desamparo y repensando acciones que tienen el potencial de generar un impacto a mediano y largo plazo.

Hasta el momento se han analizado dos ítems opuestos en el plano cartesiano en lo que respecta a la forma de abordar el tema de los inmigrantes y refugiados en el cine. Si bien se entiende que tanto el cine independiente como el cine de alto presupuesto tienen formatos, consumidores y propósitos diferentes, tenemos aquí dos vertientes que contribuyen ya sea al esclarecimiento de la situación de los inmigrantes y los refugiados en nuevos territorios, o a la generación y reafirmación de más mitos y estereotipos que perjudican de forma permanente no solo la imagen sino las posibilidades de ayuda y apoyo que este grupo de crecimiento acelerado pueda recibir a nivel local e internacional. Por ende, se pone también sobre la mesa la discusión respecto a la ética del ejercicio cinematográfico sin importar su origen, cuando tiene como objetos de estudio realidades resultado de contraposiciones políticas globales y esta población en particular debido a que el cine y las películas, como menciona Sorlin:

Vienen a ser los instrumentos de los que la sociedad dispone para ponerse en escena y mostrarse. Nunca se llevan a cabo de forma ingenua ni tampoco neutral puesto que buscan intervenir en la sociedad promoviendo y fomentando intereses diversos. De hecho, es de sobra sabido el importante papel del cine en la configuración de imaginarios populares desde el siglo pasado (1996, p. 45).
Por lo tanto, no solo hay una responsabilidad por parte del cineasta y la industria del entretenimiento al momento de presentar contenidos referentes al tema de inmigración y refugiados sino también, al momento de considerar la perspectiva desde la cual se presenta dicho contenido. Es por esto que la siguiente parte de este escrito está enfocada en las perspectivas desde las que se cuenta la crisis migratoria y de refugiados en el cine actual.

En la tercera parte del plano cartesiano se tiene la perspectiva que toman las historias en las películas cuando muestran las realidades a través de los ojos y las experiencias de los inmigrantes y refugiados, quienes se ven obligados a buscar asilo en tierras extranjeras por las crisis al interior de sus países. El propósito de mostrar el lado vulnerable de la situación de conflicto no es incentivar la lastima en el espectador, quien por lo general no va más allá de hacer comentarios en redes sociales, sino generar en él una activación del pensamiento crítico; ir más allá del pobrecito ${ }^{2}$ para permitir una reflexión en torno a los sucesos, buscando razones y explicaciones, conectando las diferentes realidades sociales para esclarecer los hechos y hallar a los responsables. Como menciona Basili, "hay una necesidad inherente al contar las historias de las víctimas que gravita hacia la responsabilidad ética ante los crímenes políticos: el vínculo entre la historia y poder" (2017, p. 44). Así, las historias contadas por los inmigrantes y refugiados donde se presente su experiencia como punto de partida, tienen el alcance de señalar culpables sin servir a una agenda política internacional.

Y nuevamente es el cine independiente el que toma la delantera y se ofrece como una herramienta y un medio para contar los sucesos desde el punto de vista de aquellos que han vivido el conflicto y en vez de tomar parte en un ciclo de guerra, han decidido escapar. Esta se puede considerar una mirada objetiva porque quien habla y recrea una sucesión de

${ }^{2}$ Pobrecito es una expresión que se usa en Colombia para denotar que se reconoce la situación de vulnerabilidad del otro y se le tiene lástima pero no hay una voluntad o acción trascendental para intentar ayudar a esta persona. 
eventos es quien ha vivido en carne propia la violencia y la desolación de la guerra. Aquí no hay televisión de por medio que edite la noticia y la censure a potestad, disfrazando cifras y protegiendo intereses particulares, aquí hay una voz con el poder de cambiar las miradas esquivas y antipáticas que pasan de opinar, ya que obliga a los espectadores a adoptar una posición respecto a la situación porque al fin y al cabo, el cine no es para escapar de la realidad sino para reflexionar sobre la misma y tomar posición activa a favor o en contra.

El cine donde se cuenta la historia de la migración y la búsqueda de asilo desde la perspectiva del que lo ha vivido, contribuye a generar una comprensión del fenómeno migratorio por parte de la población civil que se ha acostumbrado a ver a los damnificados del conflicto como cifras y amenazas. $\mathrm{Al}$ darle la oportunidad al observador de ver esta crisis desde una posición en donde se exponen las consecuencias de la guerra y la inmigración como única opción para no morir, se plantea una forma de diálogo, de comprensión del otro y hacia el otro. De esta forma, el observador reflexiona sobre la idea de que el foráneo, el inmigrante, el refugiado no es alguien que ha venido a invadir o conquistar sus territorios sino que es un individuo que está en la búsqueda de una salida al genocidio, a la crisis y a la violación de derechos humanos.

Por medio del discurso audiovisual, la persona común se puede poner en los zapatos del inmigrante o el refugiado y llegar a un nivel de empatía mínimo que se espera cambie su forma de pensar y actuar hacia los mismos. Patti Absher, quien encabezó el equipo ejecutivo del Inmigration Film Festival en Washington D.C., en entrevista para el diario El Tiempo Latino en 2016, afirmó: “Quienes vienen a ver estas películas no pueden quedarse indiferentes ante la situación de los millones de personas en Estados Unidos y de los cientos de millones en todo el mundo que huyen de las guerras, de la pobreza, de los desastres naturales y de la represión política salvaje para buscar un mejor futuro y una mejor vida" (Citada en Avendaño, 2016).
El compartir valores universales es el primer paso para el reconocimiento del otro y el entendimiento de su situación, después de todo, todos somos migrantes y así como los desplazados internos y extranjeros encuentran un hogar en nuestras tierras, nosotros hacemos lo mismo cuando buscamos mejor fortuna más allá de nuestro hemisferio.

Ya sea de manera legal o ilegal, las migraciones masivas generan la redefinición de las fronteras, el replanteamiento de las representaciones sociales de cierto tipo de poblaciones que se han estereotipado a lo largo de la historia y la negociación de la identidad nacional.

Aunque difíciles de encontrar, estas películas se han abierto paso en el mercado extranjero gracias a plataformas de streaming, más específicamente, Netflix. Esta plataforma ha llegado a codearse con los poderosos de la industria en arenas intercontinentales mientras conserva ideales de su fundación como la financiación de proyectos de alta calidad con bajo presupuesto y mensaje social. Al hacer la búsqueda en este servidor con las palabras refugiado o inmigrante, se ofrece una gran variedad de material: desde series hasta documentales y largometrajes, la mayoría en francés, español e inglés.

Esta herramienta da un alcance más significativo a la voz de los refugiados e inmigrantes, y con material de origen independiente como El médico africano (Bienvenue à Marly-Gomont, Julien Rambaldi, 2016), Refugee (Clementine Malpas y Leslie Knott, 2016) y Living On One Dollar (Chris Temple, Zach Ingrasci, Sean Leonard, 2013), el espectador encuentra posiciones claras sobre el conflicto y las formas en que esta situación social desangra a la población civil, sobre lo difícil que es ser un refugiado o inmigrante en tierras extranjeras donde abunda la discriminación, y sobre los atropellos y abusos a los que estas personas son sometidas en el día a día por parte de las personas con las que deben interactuar: desde sus vecinos hasta altos ejecutivos y trabajadores que le sirven a la burocracia gubernamental.

Es por medio de estas películas poco conocidas que el espectador da cuenta de la situación desde el otro lado, desde 
la perspectiva de quien tiene que soportar el señalamiento y la discriminación [FIGURA 4].

Así mismo, un ejemplo de películas populares y taquilleras a nivel mundial en la última década que han tenido la inmigración como temática, y que además, se cuentan desde la perspectiva del inmigrante y el refugiado es Sector 9 (District 9, Neill Blomkamp, 2009). Esta cinta se presenta como una oportunidad única para hablar sobre cómo el cine de alto presupuesto se puede involucrar con temas sociales, incluso si es de forma indirecta o metafórica, y mostrar también la perspectiva del paria. La historia de ciencia ficción, inspirada en el caso del Distrito 6 de Ciudad del Cabo, Sudáfrica durante el apartheid ${ }^{3}$, muestra a una comunidad de aliens apartada de la población civil y su subsecuente eliminación. Lo que llama la atención de esta historia es que se podría reemplazar la palabra alien por negro, asiático, latino, mujer, gay, inmigrante, refugiado, musulmán, o cualquier otra minoría, y aun así el espectador podría entender las problemáticas escondidas en la aplicación de medidas xenófobas y racistas bajo conceptos políticos y de burocracia privada.

En palabras de la filósofa francesa Simone Weil, “el enfoque en los sufrimientos de la población inocente e inerme opone a cada intento de racionalización el carácter nihilista de las masacres" (2007, p. 525). Entonces, al mostrar al otro como un igual y comprender sus motivos, sus luchas y sus esperanzas, se puede entablar un vínculo con el espectador que se espera, cambie su forma de pensar hacia aquellos que son diferentes y que esto se traduzca en sus interacciones durante la vida cotidiana.

Si bien hay temor por la naturaleza de aquellos que vienen a ocupar los territorios, también debe haber preocupación por nuestra naturaleza racista, sexista y xenofóbica porque son los nacionales (en la mayoría de los casos) los que cierran

${ }^{3}$ El Distrito 6 era el barrio más cosmopolita de Ciudad del Cabo hacia mediados del siglo XX pero fue demolido por el régimen del apartheid para construir edificios de apartamentos para personas blancas. Este hecho obligó a 60.000 habitantes a huir de la zona, convirtiéndose en desplazados internos (Filgueira, 21 de enero de 2016). los espacios y crean líneas imaginarias incorruptibles que van en detrimento de otros seres humanos y dificultan aún más su situación. Como concluye Rose (1995), hay un miedo generalizado en la población ante la idea y la realidad de la migración porque se borran los límites, no hay un adentro o un afuera, todo es abierto y se puede traspasar, por lo que esta nueva realidad no se debe entender negativa sino positiva ya que permite desdibujar barreras y mantener viva la multiculturalidad de la historia de los pueblos, producto de movimientos demográficos en el pasado.

Adicionalmente, hay un fenómeno mayoritario en las narraciones que se presentan desde la perspectiva de los refugiados e inmigrantes del que se debe hablar y es la carencia de odio y búsqueda de venganza en contra de sus opresores. No hay etiqueta de villanos, u homicidas, o la intención de crear antagonismo. Simplemente estas personas cuentan sus historias para buscar comprensión y empatía por parte de los oyentes mientras ponen a disposición el conocimiento de las atrocidades que tienen lugar en rincones del tercer mundo, auspiciadas por políticas internacionales y financiación de grupos armados ilegales.

Finalmente, la última parte a analizar está dedicada a las películas que muestran el conflicto desde la perspectiva de personas ajenas a este. Es decir, aquellos que se ven afectados de forma indirecta o aquellos que, al intentar conocer más sobre la situación, se ven envueltos en dichas formas de violencia y a través de su historia pretenden llamar la atención de la audiencia internacional.

Desde esta perspectiva se inscriben varios ejemplos, a mencionar la película The Bang Bang Club (Steven Silver, 201 1), que cuenta la vida del fotógrafo de guerra Kevin Carter durante los últimos días del apartheid en Sudáfrica y la hambruna en Sudán. Este joven fotógrafo ganó el premio Pulitzer en abril de 1994 con la fotografía de un niño hambriento siendo rodeado por un buitre. Más tarde ese año el fotógrafo se suicidó. Empero, lo relevante de esta película biográfica es analizar cómo se toma el foco de atención que se le debería 
dar a la guerra, la hambruna y los civiles que padecen están condiciones y se enfoca hacia la vida de un solo individuo. Y no es que no se deba contar esta perspectiva, ya que se cuenta la historia desde una voz testigo de los hechos, pero se toma nuevamente al agente externo y se le vuelve mártir, se le da una importancia que debería estar dirigida hacia las víctimas de la guerra, perdiendo en el proceso, el llamado a la acción social [FIGURA 5].

Otros ejemplos de historias contadas desde la perspectiva de personas ajenas al conflicto y las crisis migratorias son la producción española El cuaderno de Sara (Norberto López Amado, 2018), el documental A Place in Time (Angelina Jolie, 2007), las ficciones Amar peligrosamente (Beyond Borders, Martin Campbell, 2003), Apocalipsis ahora (Apocalypse Now, Francis Ford Coppola, 1979), Una buena mentira (The Good Lie, Philippe Falardeau, 2014) o
Amigos intocables (The Intouchables, Olivier Nakache y Eric Toledano, 2012) entre otros.

Estas producciones que pretenden mostrar a los damnificados de la guerra y las situaciones de precariedad en que viven, se ven diezmadas en su intento debido a que dan más importancia a la mirada de aquel que conoce la situación de forma superficial y su sentir hacia la misma, dejando de lado la perspectiva de inmigrantes y refugiados. Ahora bien, no es un propósito restar importancia al dolor que sienten aquellos que han perdido a su familia a manos de la violencia o que buscan respuestas en realidades ajenas y extranjeras, pero en esta búsqueda la voz de los afectados de forma directa se pierde, y nuevamente el llamado a la acción, a la denuncia, al trabajo social para la solución de conflictos se ve en un papel secundario porque los personajes principales son aquellos que viven epopeyas de descubrimiento personal y familiar
Figura 5. Portada del libro The Bang Bang Club, escrito por Greg Marinovich y João Silva y poster de la película titulada con el mismo nombre The Bang

Bang Club (Steven Silver, 2011). Fotos publicadas por el portal web Delhi Photography Club para conmemorar el día mundial de la fotografía en 2016. Se observa cómo en ambas fotos se enfoca la atención hacia los fotógrafos y no hacia las víctimas.

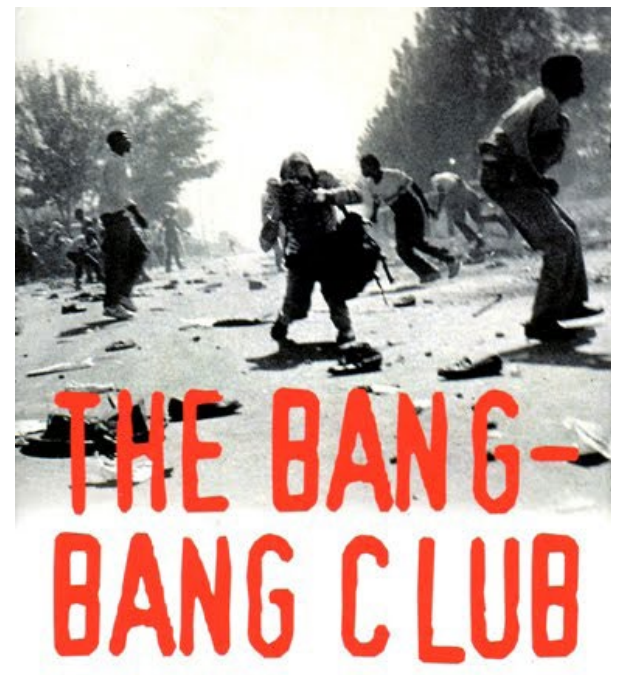

Snapshots from a Hidden War

'A book of extraordinary power. I cannot recommend it highly enough' Fergal Keane

\section{GREG MARINOVICH AND JOAO SILVA}

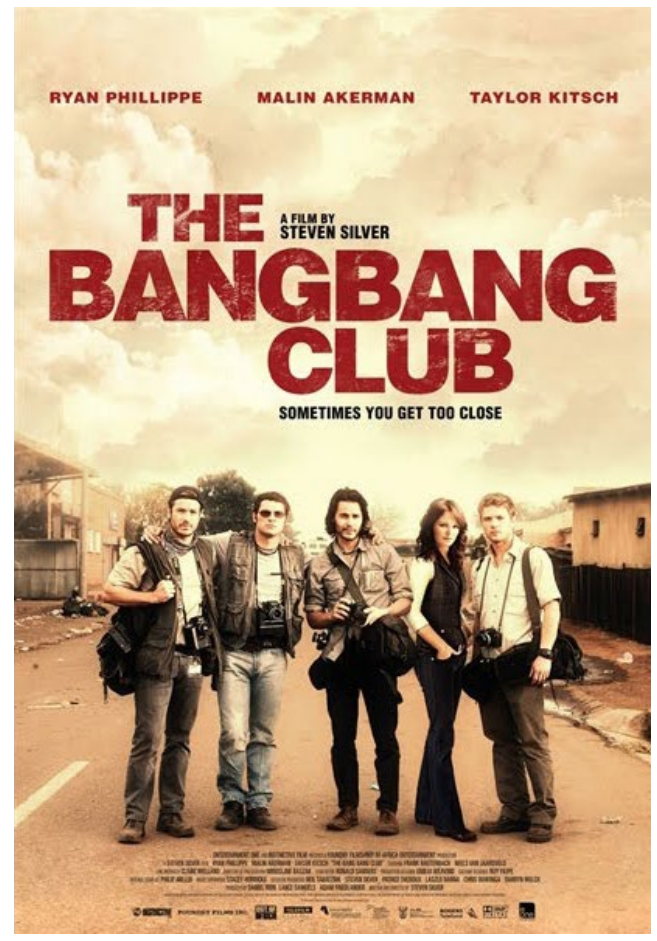


usando como medio o punto de referencia a las víctimas del conflicto internacional.

Se deja de lado la exposición de las situaciones extranjeras porque se elige un vehículo emocional ajeno a estas realidades para su presentación y análisis, alienando al observador y dejando poca cabida al entendimiento profundo de las situaciones de guerra y abuso que causan, en este caso en particular, los desplazamientos territoriales masivos. Al final de la muestra, el observador se relaciona más con el trauma del agente externo que con el del refugiado o inmigrante y se llega incluso a señalar que es su responsabilidad que alguien más se vea involucrado en estas situaciones de conflagración por el simple hecho de que se le resta importancia a su sufrimiento. De esta manera, el hombre blanco se adueña de toda realidad externa para apropiarse de esta y volverse el centro de atención.

En un estudio realizado por el profesor Charlton Mcllwain (Citado en "Cleveland: ¿tienen más atención las víctimas blancas?”, 2013), se encontró que la mujer de raza blanca ocupa un lugar de privilegio como víctima de crímenes violentos en informes de los medios de noticias. Es decir, tienen más cubrimiento mediático los hechos que involucran a alguien de raza blanca que cualquier otra historia que se origine en un grupo étnico diferente.

Como se puede observar a partir de la información previamente presentada y analizada, este fenómeno va más allá de los medios de comunicación y ha permeado la industria cinematográfica y de esto hay evidencia no solo en la forma en cómo las historias de la mayoría de grupos étnicos alrededor del mundo se han volcado hacia el egocentrismo del hombre blanco y su necesidad de hacerlo todo sobre sí mismo sino, además, en la falta de producciones reconocidas a nivel global que hablen sobre minorías, ya sean de tipo étnico, de género o religioso. La tendencia a hacer del hombre blanco el protagonista de la historia supera los intentos de los cineastas de mostrar otras realidades y frustra sus intentos de ayuda hacia otros que realmente la necesitan. Por consiguiente se vuelve necesario reflexionar sobre las formas en las que las historias se cuentan: ¿cuál es el propósito y desde qué perspectiva se hace la narración?

De esta forma, los puntos de vista desde los cuales se cuenta el fenómeno migratorio en el campo cinematográfico, -el cual se ha intensificado en la última década-, son relevantes al momento de presentar y caracterizar este grupo demográfico, porque de dichas representaciones se generan mitos, estereotipos o cambio de apreciaciones que pueden afectar de forma negativa o positiva la percepción del público respecto a los inmigrantes y refugiados, las causas de su desplazamiento, su papel en la construcción de sociedades transculturales, los retos que enfrentan para tener un futuro mejor y los compromisos de las sociedades que reciben a dichos inmigrantes. Por consiguiente, los cineastas deben entender la responsabilidad que conlleva presentar una idea sesgada a los espectadores porque esto moldea las formas en que se entienden el mundo y los damnificados de los conflictos. En palabras del director David Riker, director de la película La niña (The Girl, 2012): "Las películas pueden ser extremadamente destructivas y perjudiciales. Forman mucho de cómo la gente mira el mundo y al otro. Levantar una cámara conlleva una enorme responsabilidad" (Citado en Johnson, 23 de marzo de 2013).

A partir de los argumentos anteriormente presentados, se puede llegar a la conclusión de que el cine es una herramienta social con la tarea de llevar mensajes a la población en general, desde y hacia todos los rincones del planeta, ya sea que los observadores estén o no involucrados de forma directa con los conflictos globales en el momento actual.

Que al igual que los noticieros y los diarios, su deber es contar historias pero que, en oposición a los noticieros y los diarios, este permite al observador extender la mirada y subsecuente comprensión de las diferentes realidades, más allá de cifras o etiquetas, producto de los estigmas y prejuicios que se han creado en el imaginario de las personas y que se fomentan por las representaciones equívocas de grupos sociales marginados o en condición de vulnerabilidad, 
representaciones donde se origina la desinformación del estado de guerra y crisis actual.

Por lo tanto, el cine se presenta como una herramienta y un medio para darle voz a aquellos que son víctimas de los conflictos bélicos globales y viven las consecuencias de dichos conflictos debido a la indulgencia que caracteriza a la comunidad internacional representada por cortes internacionales y tratados. De igual forma, el cine es responsable de las ideas que presenta y las formas de representar a los individuos que se ven involucrados en las crisis internacionales, razón por la cual se debe estudiar y analizar detenidamente el contenido, no solo desde la perspectiva de aquel que decide crear y contar historias con temática de inmigración y sus propósitos con dicho material, sino también desde las perspectivas del protagonista (bien sea el inmigrante, el refugiado, o un agente externo), considerando a la vez los posibles cambios de paradigmas por parte del espectador a partir de la recepción de la información presentada.
Es por estas razones que el cine con temática de inmigración debería tener como principios el generar debate y representar a tantos grupos demográficos alrededor del mundo como sea posible, ya que un cine excluyente demuestra las falencias sociales al momento de excluir a ciertos individuos, dejando espacio para los estigmas, los prejuicios y el fomento de representaciones erróneas que dificultan los procesos de aceptación y apertura cultural con los otros. López Aguilera (2010) hace referencia a la directora Jennifer Kent cuando reflexiona sobre cómo el cine es un espejo del mundo y sus realidades por lo que, si el cine representa solo a una parte de la población (por lo general la parte privilegiada) no está haciendo su trabajo y en este vacío de información no se permite eliminar la culpa que se imputa a las víctimas por situaciones creadas por políticas inconsistentes que perpetúan el modelo de gestión de poder. 
Avendaño, A. (28 de octubre de 2016). Cine e inmigrantes. El Tiempo Latino. Recuperado de http://eltiempolatino.com/news/2016/oct/28/cine-e-inmigrantes/

BASILI, C. (2017). La memoria de los vencidos: historia y justicia en el pensamiento de Simone Weil. Revista de Filosofia, 42(1), 41-57. doi: http://dx.doi.org/10.5209/ RESF.55446

Castillo, M. (20 de octubre de 2017). Hollywood's Diversity Problem and Undocumented Immigrants. The New York Times. Recuperado de https://www.nytimes. com/2017/10/20/movies/dreamers-undocumented-immigrants-hollywood.html

Cleveland, ¿tienen más atención las víctimas blancas? (9 de mayo de 2013). BBC Neres. Recuperado de: https://www.bbc.com/mundo/noticias/2013/05/130509_cleveland_secuestros_mujeres_blancas_atencion_medios_men

Filgueira, E. (21 de enero de 2016). El District Six Museum de Ciudad del Cabo (Sudáfrica): El museo de un barrio que no existe. Mundo Negro. Recuperado de http://mundonegro.es/el-district-six-museum-de-ciudad-del-cabo-sudafrica-elmuseo-de-un-barrio-que-no-existe/

Galiano León, M. (2008). Movimientos migratorios y cine. Historia Actual Online, (15), 171-183. Recuperado de https://www.historia-actual.org/Publicaciones/index. $\mathrm{php} / \mathrm{hao} / \mathrm{article} / \mathrm{view} / 243$

Johnson, R. (23 de marzo de 2013). Cinema's Shifting Perspective On Immigration. Los Angeles Times. Recuperado de https://www.latimes.com/entertainment/ movies/la-xpm-2013-mar-23-la-ca-mn-immigration-films-20130324-story.html

LóPez Aguilera, A. M. (2010). Cine e inmigración: espacios de inclusión y exclusión. (Tesis de Maestría). University of Nebraska, Estados Unidos. Recuperado de http:// digitalcommons.unl.edu/modlangdiss/8

Martínez-Salanova Sánchez, E. (2008). Cine e inmigración: otra ventana abierta para el debate. Cómo expresan los medios de comunicación la emigración, el mestizaje y las relaciones interétnicas. En F. Checa y Olmos (Coord.), La inmigración sale a la calle: comunicación y discursos políticos sobre el fenómeno migratorio (pp. 231-252). Barcelona, España: Icaria.

Roch, G. (10 de marzo de 2016). Siete cortometrajes sobre personas refugiadas recomendados por educadores en derechos humanos. Amnistía Internacional. Recuperado de https://www.amnesty.org/es/latest/education/2016/03/ seven-free-short-films-about-refugees-recommended-by-human-rights-educators/

Rose, G. (1995). Place and Identity: A Sense of Place. En D. Massey y P.M. Jess (Coords.), A Place in the World? Places, Cultures and Globalization (pp. 87-132). Oxford, Reino Unido: Oxford University Press. 
SAnguino,J.(16 dejunio de 2016). Hollywood ya novende: el cine se enfrentaa supeoraño en un siglo. Vanity Fair. Recuperado de http:/ /www.revistavanityfair.es/actualidad/ cine/articulos/el-peorano-de-hollywood-fracasos-de-cine-en-2016/22491

Sorlin, P. (1996). Cines europeos, Sociedades europeas, 1939-1990. Barcelona, España: Paidós.

WeIL, S. (2007). Escritos históricos y políticos. Madrid, España: Trotta.

\section{Filmografía}

Audiard, J. (Director) \& Caucheteux, P. y Sorlat, G. (Productores). (2015). Dheepan. Francia: Why Not Productions, Page 114, France 2 Cinéma.

Rambaldi, J. (Director) \& Delbosc, O., Duhault, P. y Missonier, M. (Productores). (2016). El médico africano [Bienvenue à Marly-Gomont]. Francia: E.D.I. Films, Curiosa Films, Moana Films, TF1 Films Production.

Silver, S. (Director) \& Samuels, L. y Welland, C. (Productores). (2010). The Bang

Bang Club. Canadá: Foundy Films, Instinctive Film, Out of Africa Entertainment, The Harold Greenberg Fund.

Zwick, E. (Director \& Productor) \& Gorfill, G., Herskovitz, M., King, G. y Weinstein, P. (Productores). (2006). Diamante de sangre [Blood Diamond]. Estados Unidos: Warner Bros., Bedford Falls, Virtual Studios, Spring Creek Productions.

Shannon Estefannia Casallas Duque (Colombia) es Licenciada en Educación Básica con Énfasis en Inglés, y Especialista en Infancia, Cultura y Desarrollo de la Universidad Distrital Francisco José de Caldas en Bogotá, Colombia. Escritora publicada en revistas especializadas en cine, creación literaria, investigación educativa e investigación social. En la actualidad radica en Estados Unidos. 